\title{
Mystique in Arabic Poetics: An Inquiry into Cultural Dominant
}

\author{
Yassir Mohammed Nasr Ali \\ Faculty of Arts, Hodeidah University, Hodeidah, Yemen \\ Email: yassir mohammed77@yahoo.com
}

Received 7 December 2014; accepted 21 December 2014; published 13 January 2015

Copyright (C) 2015 by author and Scientific Research Publishing Inc.

This work is licensed under the Creative Commons Attribution International License (CC BY). http://creativecommons.org/licenses/by/4.0/

c) (i) Open Access

\begin{abstract}
This paper argues that the paucity of innovative work in Arabic critical tradition is a ramification of an aesthetic of conformity to the dominant patterns in Arabia. The preoccupation with specific aspects in poetics does not contribute to the framing of intellectual debates past and present, but discloses an exclusionary discourse with a narrow scheme of knowledge. Such a limitation in epistemology is symptomatic of a wider one at the level of formative ideals. The present article attempts to unfold the crisis in this epistemology by problematizing the mainstream poetics of culture and seeking new possibilities of reflection beyond the edges of definition.
\end{abstract}

\section{Keywords}

Critical Assumptions, Cultural Dominant, Unfolding the Crisis, Revaluation of Heritage, Metaphysics of Adequacy, Beyond the Crisis

\section{Critical Assumptions}

The critical anchors of poetics are cast into the moorings of ancient Arabic poetry as a repertoire of cultural heritage to be maintained and emulated by succeeding generations. Endowed with a canonical status, this poetry forms a "model for correct usage," while its “discourse principles and imagery” are a "yardstick by which later critics of a conservative bent judged the 'naturalness' of Arabic poetry” (Allen, 1989: p. 364). The internal harmony of the poem bespeaks an ingrained enchantment with fascinating expressions and splendid tropes, so does the concern do with classical tributes of the genius of craftsmanship and grandeur of style. In addition to the strident emphasis on poetic lineage, ancient Arabic poetry enjoys a privileged position in Arabia and is, thus, taken as definitive of the scope and interests of subsequent critical activities.

Arabic poetics conceives of the poem as an autonomous entity, an aesthetically motivated totality with an overwhelming sensuous power. Premised on the notion of muhâkâh "imitation", art is not isomorphic with real- 
ity, nor is it a duplication of the raw flux or flow of actuality. Rather, art is a distinct order of imaginative activity that is both energized with its own inner life and free from extraneous influences (Ismail, 1922: p. 335). In Arabic Poetry in the Golden Age, Vincete Cantarino (1975) explains the imitative theory of Arabic poetry: "Imitation was not naturally concerned with either the intrinsic moral or real values or acts, but only insofar as they were the cause of an aesthetic delight in the soul of the percipient one" (86). The poet may draw on material from the external world of reality, but with his artistic genius he weaves "another life" of artistic novelty and wondrous beauty beyond the quotidian of actuality (99). Therefore, delving into the aesthetic and elucidating its rapturous power are the main focal points in traditional Arabic criticism.

The preoccupation with lyrical properties and intrinsic aspects aims at heightening one's perception of the myriad forms of beauty in art. The sobriety of expression and subtlety of figurative language are thought of as sources of pleasure, for instance. Because the ancient Arabic poem is characterized by a "profound congruence between vocal and acoustic values of speech" and "emotional and affective content" (Adonis, 2003, Poetics 14), poetic felicity is defined as an orchestrated symphony of internal tributaries-rhyme, rhythm, similes, metaphors, wording, rhetorical devises, and stylistic embellishments (Van Gelder, 1982, p. 28). Every formalistic aspect is perceived as contributing to deepening the overall effect of artistic ecstasy.

Besides, Arabic poetics exhibits a massive interest in form as the essence of creativity. This concern springs from the deeply rooted concept of "unity of content and diversity of expression" (Adonis, 2003, Poetics 14); the conceptual contents of poetry usually relate to matters common to one and all, while formalistic techniques are singular. The architectonic of the artefact is distinctive of artists. What distinguishes poems is not as much the profundity of thought as the verbal dexterity and moving lyricism of the poetic feel and flair of the deployed forms; that is, how the poem is composed matters more than what it says. Hence, the intrinsic worth of the poem is its weight in evaluation. Accordingly, poetry is defined as "kalâm mawzûn muqaff $\hat{a}$, a rhythmic and rhymed speech" (Cantarino 44), thus focusing largely on formalistic aspects rather than cognitive ones.

Literary appreciation takes the form of impressionistic, laconic responses to the affective appeal of poetry. Under the spell of the sensuous power of the verse, the intense feelings aroused in the reader or listener are given vent to in terms of an amalgam of haphazardly articulated phrases of explanatory nature (Al-Rabi'I, 1996, p. 19). As "a temporary effect and a fast reaction without comprehensive or long thinking” (Ibrahim, p. 35), criticism does not proceed along methodological lines of analysis and rigorous reasoning. This is mainly because Arabic poetics espouses an end-oriented hermeneutics; the focus is on the end product of the literary experience with no reference to the processes through which meaning is made. As the meaning-making process remains a mystique, meaning esoteric, knowledge hermetic, what criticism offers is passionate articulations of impressions that are bereft of rigorous analytic reasoning.

The idiosyncratic explications of the verse occur at the micro-level of a single line or a short fragment. According to the prominent critic Mohammed Mandoor (1996), Arabic literature is a literature of particulars in which the primary unit of analysis is the one line of the poem (153). To assess the merit of a poem, it suffices the purpose to attend to one of its parts since all are innately the same. Because of such homogenizing conception and "atomistic" tendency (Stetkevych, 1989: p. 29), Arabic poetics universalizes the particular, sponsoring a universalist outlook that does not pay as much attention to differences as to commonalities. By relegating singularities of experience and peculiarities of expression to the background of critical activity, the established tradition of criticism espouses an essentialist poetics in which novelty is sacrificed for keeping intact the norm.

This absence of in-depth understanding of the complexity of thought is furthered through representing the poet as a mouthpiece of his tribe. Because the nature of his poem-panegyric, lampoon, eulogy, love, pride, or satire- depends largely on the immediate concerns of the community (Al-Shihri, 2000, p. 58), the poet is a medium for addressing causes greater than himself; he is a catalyzing agency for conceptualizing the perceptual collective in terms of the poetic individual. The poet's individuality is fulfilled by immersing it into the wider questions of the collectivity. Such impersonalizing impulse does not aim at achieving objectivity, but is an embodiment of the nature and culture of its homeland—an idiom of expression in the "concrete", a language of "few abstractions", a philosophy of "pithy sayings", a personal in terms of an impersonal, and an individual in the voice of the collective (Gibb, 1963: p. 34).

As the discussion above shows, the traditional status of Arabic poetics draws inspiration from an aesthetic of verisimilitude, according to which everything is conceived and conceptualized in the images of some ancient exemplars. The present conforms to the prescriptions of the past; it is a hermeneutics of closure that is not subject to contingencies of history. Like beads of a rosary, the critical assumptions in Arabic critical tradition are framed to 
create aesthetic sensibility of a universalist metaphysics of meaning beyond temporality (Al-Musawi, 2006, p. 6).

\section{Cultural Dominant}

The Arab world is a site of contestation of forces with diverse ideologies (i.e., traditional, mystical, rational, modern, and national), of which the traditional discourse stands supreme and unmatched. Represented as essentially theo-centric, this discourse lays exclusive claims to truth as revealed in pristine Islam and, hence, attains unsurpassed social and political support. In Islamic Philosophy from Its Origin to the Present, the renown Muslim scholar Seyyed Hossein Nasr (2006) elaborates on the doctrines of the traditional stream as "archetypal realities in the universe" (227), beyond which every other voice is simply peripheral. He writes: "The few in the Islamic world who would cut this cord of reliance and declare the independence of reason from both revelation and intuition were never accepted into the mainstream of Islamic thought. They remained marginal figures" (264). "[I]n the land of prophecy," as he argues, the traditional paradigm contains the seeds of the "wisdom" of "Islamic revelation" and, hence, is "the ground upon which the religion is based" (271). With such powerful cultural capital, the fate of the traditional paradigm is internalized and perpetuated as the fate of the whole ArabMuslim community.

The dominant paradigm in Arabia comes in the moderate dimension of a centrist culture that nurtures conservative views about discipline, reality, norms, knowledge, and stability. Didactic in orientation, the traditional paradigm pays a great deal of stress on ethics as the guiding principles for all one's deeds. Tradition prescribes rules of thinking and behaviour that contribute to moulding the character and preserving norms of grace and decency. The concern with nourishing such a morality of holding high societal mores and of literally abiding by traditions surpasses every other concern of the establishment.

Endowed with unquestioned authority, the traditional deployment of cultural resources validates specific structures of knowledge and furnishes certain acts of representation as legitimate and healthy to the well-being of the individual and the welfare of the state (Arkoun, 1988, Arab Thought 52). The rationale for stipulating conditions for knowledge formation resides in the concern to eliminate spectrums of thought with divergent orientations, for they have the potential to seduce minds into derailed tracks of deviation from the path of truth as mapped out by traditional authorities down the centuries.

Beneath the protectionist poetics of the cultural dominant, as the British historian of religions Karen Armstrong (2000) argues, are two correlated facts. First, communal welfare takes precedence over individual gains; precisely because, "social stability and order" are "more important than freedom of expression" (34). Ensuring the uninterrupted continuity of the held order outweighs all acts of individual innovation. Second, underlying this culture is mythic consciousness, which creates "a cast of mind that adapts and conforms to the way things are" (35). As all-pervading cultural codes, myths and rituals have a fundamental role in uniting members of the ummah [community] present and past and are crucial to strengthening the rhetoric of the held discursive thought structures through lulling minds in superstitions. In so doing, the dominant authority succeeds in driving consciousness into hibernation and in tightening its fist on real courses of action.

Besides, the emphasis on conformity to conventional principles is particularly explicit in the profound reverence attributed to received traditions and inherited values. Thereupon, strict adherence to moral standards is undisputable, and individuals need to abide literally by everything handed down to them via mainstream institutions and centres of learning. The weight of such cultural sacred is depicted as paramount in shaping subjectivities and directing knowledge and research. Inculcated into hearts and minds are specific meanings and memories of formative moments in the history of Arabic-Islamic civilization. Such narratives and accounts are represented as pregnant with rare treasures of meaning and profound truth despite time and space. For this sacrality, received traditions of thought are alleged to be the criteria for legitimating, assessing, or refuting any endeavour.

It is not surprising then that the portrait of the self is punctuated with the demands and directions of the mainstream ideology. Individual agency is measured against a background of compliance with the terms by which the society moves and reacts (Al-Musawi, 2006, p. 16); individuality is identification with the held premises. Human fulfillment is defined in terms of serving the causes of the existing order, deepening the spell of its influence, and safeguarding its sanctuary.

Thus, one could argue that the cultural poetics of the dominant paradigm is characterized by a unidimensional mode of thinking, a monologic discourse, an overriding concern for self-preservation, and a highly prescriptive mode of instruction. Such features bespeak a monolithic entity of narrow territorial imperatives. Underlying all 
of this is the status quo of containment that is characteristic of authoritarian ideologies and totalitarian regimes.

\section{Unfolding Crisis}

In Arabic poetics, the critical spirit is in essence reflectionist. The self-independence of the artefact does not imply independent thinking and free expression, but rather restricts the scope of creativity to addressing cosmetic frills and superfluous aspects. Arabic poetics does not stimulate thinking "outside the box" of conventionality, either. It nurtures a shiftless cast of mind that addresses but what tradition allows and affirms but what fixtures validate. Beneath this explicit aggrandizement of tradition, however, is an implicit demonization of what falls beyond the commonplace. Such theoretical closure is inimical to developing critical consciousness of rhetorical devices and linguistic resources, of realities and promises, of changes and challenges, and of what it means and takes to create citizens of the world. Falling short of reflexivity is the diagnosis of the crisis in Arabic poetics.

As a consequence of the authoritarian practices of the traditional paradigm, the intellectual atmosphere lapses into insignificance, diminishing productivity and reducing potentiality across the board. "The hegemonic circulation of dry language, stagnant referentiality, and application of the dormant and the backward" wish only "to enforce and sustain power relations" (Musawi xiv). In other words, the melodramatic rhetoric of the traditional discourse is instrumental to manipulating the public and combating opposition; the dominant paradigm is a discourse of confinement. As pointed out earlier, the current paper attempts to look into the epistemological grounds the cultural dominant adduces to justify its rejectionist stance to innovation and modernity. In the subsequent parts of the article, section (A) addresses an array of critical reflections on the existing crisis in the Arab world as advanced in the contributions of major thinkers towards a reevaluation of Arabic-Islamic heritage, while (B) is the investigator's bone of contention.

A. Revaluation of Heritage

In contemporary critiques of Arabic-Islamic intellectual civilization, prominent writers and critics describe Arabic epistemology as in a state of crisis, on grounds of the enormous influence of the traditional discourse on all spheres of life. In Historicity of Arabic-Islamic Thought, Mohammed Arkoun (1996) problematizes the theological orthodoxy of the dominant patterns in the Arab world as at the root of stagnation and decline (13). The collaboration of the traditional streams with the ruling classes aims at furthering their influence on all sections of society (19-20). The traditional forces impose specific versions of reality as the cultural sacred, to the exclusion of other versions and interpretations. This ideological exploitation of religion serves political aspirations of hegemonic agenda. It is the mutual interest between religious authorities and political forces that suppresses all calls for change as outrageous of the cultural sacred, thus inviting retribution. This rhetoric of intimidation is what essentially sustains the existing social arrangements.

The Syrian-Lebanese poet-critic Adonis (pseudonym of Ali Ahmad Sa'eed) ascribes the conceptual rigidity in the Arab world to an obsession with the held premises of the traditional patterns and to the suffocation of all dynamic impulses of modernity. He explores the ideological underpinnings of the mainstream culture:

This traditionalist culture is embodied in the uninterrupted practice of an epistemological method which sees truth as existing in the text, not in experience or reality; this truth is given definitively and finally and there is no other. The role of thought is to explain and teach, proceeding from a belief in this truth, and not to search and question in order to arrive at new, conflicting truths. (Poetics 78)

In The Static and the Dynamic, Adonis (1974-1979) continues to explain that the "traditionalist" pattern of Arabic-Islamic culture does not tolerate voices of dissent, nor does it provide a space to consider alternative possibilities. Exclusive and monologic, "traditionalist" discourse offers its "static" versions as embodiment of religion itself, thus promoting its politically motivated interpretations as the cultural sacred. Moreover, such a discourse perpetuates: 1) docile surrender of the individual and firm faith in the all pervasive power of absolutism, 2) fixation with the past and fear from the unknown, 3) primacy of content over form as the former is the undisputable given, and 4) conflict with anything modern (Static 1: pp. 58-62). Therefore, subordinating the "dynamic" to the "static" of the "traditionalist" culture is the prime cause for the prevalent stagnation (Static 3: p. 244). The self-enclosed and past-centred culture of this paradigm, as Adonis states, precipitates the fall into dogmatic shackles and dins of ignorance (Static 4: p. 217). As an iconoclast, he sees that the way out of the crisis consists in bringing about a radical transformation of traditional culture through appropriating the creative spirit of Western modernity as "the most revolutionary development in the history of mankind" (Poetics pp. 91-92). 
In Contemporary Arab Thought, Ibrahim M. Abu-Rabi' (2004) locates the crisis engulfing the Arab world in the upper hand of the traditional intelligentsia (360). Unearthing the causes of social immobility, he points at taqlid [imitation] as the first and foremost factor to be addressed in this regard (366). The traditional emphasis on conformity as the essential mode of existence and functioning culminates in producing passive mentalities that merely reproduce same, though at times different but superficially, products. This objectification and defeat of human inquiring spirit is the life-force for traditional institutions and political constituencies, shaping subjectivities and manipulating directions of knowledge with a view only to feathering their own nest. Abu-Rabi' also remarks that the unequal distribution of wealth and the concentration of power in a few hands eventuate in deteriorating the material conditions of life and constraining creativity (374). Not only does the unquestioned authority of traditional forces curb the productive potential of society through policing activities, but it also implements policies of degradation and enfeeblement at all levels.

The conformist poetics of tradition is also delineated as the cause of crisis in the Arab world as reflected in many critiques offered by the Saudi critic Abdullah Mohammed Al-Gathami (1991). In The Stance to Modernity, he observes that the hegemonic practices of the traditional stream drains minds of creative potential and turns them into slaves to custom (40). This cultural enslavement continues to keep minds in hibernation. The crisis in Arabic poetics, as he continues to elaborate, stems from an epistemological limitation caused by three main factors: 1) Having no critical stance, 2) Having no understanding of the philosophy of innovation and the concept of modernity, and 3) Having a limited view of language (56). What Al-Gathami calls the "crisis of creativity and criticism" is, therefore, a translation of the blind subservience of the critical to the parameters of the cultural dominant, and of the collapse of epistemological scholarship into the precipice of metaphysical conceptions.

What cuts across most of the contemporary critiques of Arabic-Islamic heritage is a strident emphasis on the explicit poetics of conformity and the implicit politics of opportunism that characterize the modus operandi of the traditional paradigm. In his ambitious project of cultural rejuvenation, the Moroccan philosopher Mohammed Abed Al-Jabri (b. 1935) desediments the hidden layers of Arabic interiority. In Problematiques of Contemporary Arabic Discourse (1988) and the four volumes of Critique of Arab Mind (1984-2007): 1) تكوين العقل العربي [Composition of Arab Mind] (1+ بنية العقل العربي (Structure of Arab Mind]

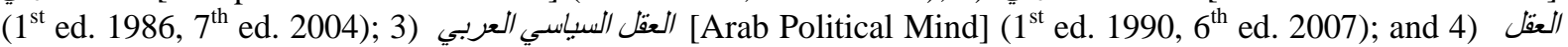
الأخلاقي العربي [Arab Ethical Mind] (1 $1^{\text {st }}$ ed. 2001, $2^{\text {nd }}$ ed. 2006), Al-Jabri (2007) finds conformity as a repercussion of an entrenched obsession with "origin". He argues that "origin" is internalized as the exclusive frame of reference and the most authentic source of guidance. "Origin", as he points out, refers to the inherited traditions of religious rulings and instructions that are held as criteria for the "construction of knowledge" (Critique 2: 113-16). It is a logo-centric culture that does not allow for deviation from its foundations.

The obsession with "origin" also discloses another dimension of Arabic inwardness: fixation with the past. Romanticized images of grandiose moments in the past are sources of life for Arabic mind, and are the last resort particularly at times of crisis. The enchantment with the past takes on growing significance with the progress of time. The drama of confrontation between Arab-Muslim self and modern realities of the present, however, exposes the inefficacy of the inherited forms of hermeneutics to make intelligible, let alone respond appropriately to, much of the cacophony of the zeitgeist (Al-Jabri, Problematiques 34). This drama continues to hold the self in paralysis so long as the conflict remains irresolvable, and the traditional streams keep nurturing grounds that are fundamentally resistant to modern ways of living and thinking. The interface of such divergent worldviews (i.e., tradition vs. modernity) is a problematique, as Al-Jabri states, the resolution of which calls for a reconstitution of the entire corpus of tradition (Problematiques 184).

The narrow ideological fixtures of the traditional discourse, as it is clear, clamp down all activities outside its orbit and disembody consciousness of all impulses to make new crossings. Instrumental to this discourse is a manipulative rhetoric which plays an interventionist role between single innovative acts and communally accepted norms, a role that considers innovation deviation, that filters consciousness from sullied thought, and that reminds one and all of the path of truth as prescribed in the existing accounts of received traditions.

B. Metaphysics of Adequacy

Paradigmatic of traditional culture is a metaphysics of adequacy that mediates between the monopoly of knowledge and the seizure of power. The metaphysics of adequacy characterizes the existing traditions as a selfsufficient entity, with categories of thought and methods of interpretation that offer full guidance on all matters and occasions. The meaning of everything is represented as already in there, completed, closed, and finalized awaiting unproblematic re-experience by individual human beings. No stone is left unturned by earlier genera- 
tions of scholars and religious authorities; as such, traditional knowledge is to be imbibed wholeheartedly as a matter of celebration that all members of this culture are to take part in, affirm, and continue holding on to.

The metaphysics of adequacy is a rhetorical construct that renders sacred the traditional interpretations of formative moments in Islamic history. These interpretations are taken up to crystallize the pristine forms of Islam (Nasr, 2006: p. 260), as divinely revelations and infallible instructions, over and beyond which any quest for truth is deemed outrageous. Consequently, on no account is need felt to seek fresh avenues of thought other than the established ones (Arkoun, 1988, Arab Thought 52). Remarkable as it is that the overemphasis on the metaphysics of adequacy relies on its function both as proactive and as preemptive: "adequacy" represents the traditional discourse as the authentic source of unquestioned knowledge, thus dislodging other competing discourses, and preempts prospects of criticism that might be laid at its door. It then follows that the weight of traditionalism in any part of society is gauged against the scale and degree of the spell of influence the metaphysics of adequacy exercises on that part; the deeper entrenched the notion of adequacy in consciousness, the more secure the position of traditional forces. As such, one would argue that the halo and mystique of the traditional means of knowledge would continue to support their prestigious status as long as the knowledge-power nexus continues to be filtered by the metaphysics of adequacy.

The ramifications of the metaphysics of adequacy on Arabic poetics are massive, particularly in terms of reducing critical reflection to matters of aesthetic considerations. The preoccupation with the aesthetic, though necessary, is not enough and is a cause of crisis in the knowledge-making processes: poetics is not effective in furnishing critically equipped responses to, and explanations of, the logicality of today's cultural logic. Arabic poetics, as it stands, fails to account for the pluridimensional character of the human complex and for the logic of transience that characterizes all syndromes of thought in time. Not only do the critical monism and the anachronistic practices of interpretation in poetics diminish the thrill of experiences in the realm of art, subvert individual mobility, and marginalize different experiences, but they also function as ideological tools for indoctrinating minds and shaping individualities. In other words, owing to the pervasive presence of the metaphysics of adequacy in the interiority of the dominant patterns, Arabic poetics continues to recycle the same old concepts and concerns, formalizing intellectual activity, disembodying consciousness, and immobilizing cultural resources.

The crisis in Arabic critical tradition is a miniature of a wider one at the level of culture. Consequent to the prevailing conception of a fully-fledged culture, human activity as a whole is defined merely in terms of refashioning heritage and re-affirming its continuity. Thus acculturated, one and all are bound to mechanically and blindly reproduce the held ideals of the establishment; the traditional resources of meaning and knowledge are inculcated as adequate enough to meet all social needs of all times. The presupposition of the metaphysics of adequacy leaves no room for initiating new levels of critical reflection, but demands regurgitating the traditionally structured premises. Such politics of containment perhaps explains the defensive stance the traditional forces usually take in encountering other systems of thought, particularly those with subversive reading practices.

The nexus of the critical and the cultural is formulated along a relationship of symbiotic compatibility via the catalyst of adequacy. The strident stress on poetic lineage in Arabic poetics is an allotrope for partisanship and allegiance to the existing order; the critical task is defined as an upholder of tradition (Arkoun, 1988, Arab Thought 52). Keeping intact cultural heritage as validated by tradition, uncontaminated by strange incursions and devoted to its culturally sealed task, the self-enclosed and logo-centric poetics of Arabic tradition functions as a knee-capper to, and a reworking of, the formative ideals of the cultural dominant. The dominant rhetoric in its turn sanctifies the critical tradition as an exemplary repository of original values, whose contours are symbolic of the boundaries of the traditional sacred itself. It is interesting to remark that representing critical conventions as embodiments of the inwardness of Arabic-Islamic culture is a tactic for auto-immunizing the citadel of the dominant culture through freezing critical activity and for promoting the cultural poetics of the mainstream.

As it is obvious the "recipe" for political gains is the unrelenting representations of knowledge as a mystique with esoteric meanings and hermetic practices. And since the essence of such knowledge is mapped out as a metaphysical realm, its "adequacy" refutes every counterclaim. The maintenance of the metaphysics of adequacy is what legitimates the traditional paradigm as the cultural dominant and ensures its continuity.

\section{Beyond Crisis}

A critical exposé of the politics of the cultural dominant is a point of departure for transformation. Reevaluating 
the validity, reliability, and viability of received traditions of thought is central to awakening consciousness from lethargy of custom and to emancipating it from the codified grooves of the metaphysics of adequacy and unenlightened complacency. Inquiring into what lurks behind what is usually taken for granted is the launching pad for inaugurating a new era of intellectual illumination and for battering down walls of ignorance.

For this revisionism to see the broad light of the day, there must be a critical awareness of the "realities" of the dominant discourse. Therein lies the role of the intelligentsia. Part of this role is to draw a clear line of demarcation between the religion of Islam as a heavenly creed and as a blueprint for life in its abundant forms and the religiosity of the traditional currents as worldly institutions with ideologies, protocols, and interests for power-seeking. "These forces manipulate theological discourse to preempt criticism and equate power control with religious infallibility" (Al-Musawi, 2006, p. 62). The metaphysics of adequacy needs to be exposed in terms of the wider network of filiations and affiliations it has with authorities-traditional and political. Reviewing the epistemological grounds of the whole metaphysical conceptions in circulation is crucial to promoting better understanding of received categories of knowledge and to formulating fresh ones. Disseminating such knowledge helps demystify a great deal of confusion, revise much of what is taken for granted, and unleash dormant energies for thinking and rethinking all afresh.

The intellectuals need also to set up forums for debating the existing state of affairs in the Arab world and assessing the repercussions on its larger picture, for negotiating possibilities of transformation as envisaged by different voices, and for developing reflexivity by opening up fresh epistemic sites for addressing wider comparative cultural poetics. Indeed, what needs addressing is rethinking the whole philosophy of education along new lines of pedagogical and cultural dynamics that keep abreast of advances in sciences and knowledge and bear relevance to the concerns and aspirations of all sections of society.

Of paramount significance to any project of cultural rejuvenation is also the introduction of the culture of difference as an existential necessity for promoting peaceful coexistence and complementary relations among human collectivities beyond all sectarian imperatives. The traditional stereotypes of the "Other" as a source of potential threat to the self need to be replaced with a different paradigm that celebrates difference and acknowledges the "Other" as the unknown part of the self and as a partner in construing, constructing, and reconstructing everything in temporality. Such a culture of "thinking together differently" breaks the wall and bridges the divide, dismantles politically fabricated barriers of hostility, and embraces a new hermeneutics of dialogue beyond difference.

Such a revisionist enterprise is undoubtedly institutional, but has seeds dormant in realizing the enormity of the crisis engulfing one and all. Developing such societal awareness is conducive to both mobilizing the public and initiating transformative projects; it is a commitment to causes greater than the self and a collective responsibility beyond all edges of definition.

\section{References}

Abu-Rabi', I. M. (2004). Contemporary Arab Thought: Studies in Post-1967 Arab Intellectual History. London: Pluto.

Adonis (1974-1979). The Static and the Dynamic: A Research into the Creative and the Imitative of Arabs. Beirut: Saqi.

Adonis (2003). An Introduction to Arab Poetics. London: Saqi.

Al-Gathami, A. M. (1991). The Stance to Modernity and Other Issues (2nd ed.).

Al-Jabri, M. A. (2007). Structure of Arab Mind. Vol. 2 of Critique of Arab Mind. Beirut: Markaz Dirasat Al-Wihda Al-Arabia.

Allen, R. (1989). The Arabic Literary Heritage: The Development of Its Genres and Criticism. Cambridge: Cambridge UP.

Al-Musawi, M. J. (2006). Arabic Poetry: Trajectories of Modernity and Tradition. London: Routledge.

Al-Rabi'i, H. S. K. (1996). مقاييس البلاغة بين الأدباء و العلداء (Criteria of Eloquence between Artists and Scientists). Makkah: Umm Al-Qura U.

Al-Shihri, Z. I. A. (2000). من صور التلقي في النقد العربي القديم (Of the Modes of Reception in Ancient Arabic Poetics). Scientific Journal (Humanistic and Administrative Sciences), 1, 57-76.

Arkoun, M. (1988). Arab Thought. New Delhi: Chanda.

Arkoun, M. (1996). Historicity of Arabic-Islamic Thought (2nd ed.). Beirut: Al-Enmaa’ Al-Qawmi Centre.

Armstrong, K. (2000). The Battle for God. New York: Ballatine.

Cantarino, V. (1975). Arabic Poetics in the Golden Age. Leiden: Brill. 
Gibb, H. A. R. (1963) Arabic Literature: An Introduction (2nd ed.). London: Oxford UP.

Ibrahim, T. A. تاريخ النقد الأدبي عند العرب: من العصر الجاهلي الى القرن الرابع الهجري (History of Literary Criticism of Arabs: From the Age of Ignorance to the Fourth Century Hijri “Muslim Calendar”). Egypt.

Ismail, E. A. D. (1922) أصول الجمالية في النقد العربي: عرض و تفسبر و مقارنه (The Aesthetic Fundamentals in Arabic Criticism: Demonstration, Interpretation, and Comparison). Cairo: Al-Fiqr Al-Arabi.

Mandoor, M. (1996) النقد الهنجي عند العرب: منهج البحث في الأبب و الن (The Methodological Criticism of Arabs: Research Methodology in Literature and Criticism). Cairo: Nahdat Misr.

Nasr, S. H. (2006) Islamic Philosophy from Its Origin to the Present: Philosophy in the Land of Prophecy. New York: State U of New York P.

Stetkevych (1989) Intoxication and Immortality: Wine and Associated Imagery in Al-Ma'arri’s Garden. In Roger Allen et al. (Eds.), Critical Pilgrimages: Studies in Arabic Literary Tradition (pp. 29-48). Austin: Lit. East and West.

Van Gelder, G. J. H. (1982) Beyond the Lines: Classical Arabic Literary Critics on the Coherence and Unity of the Poem. Leiden: Brill. 
Scientific Research Publishing (SCIRP) is one of the largest Open Access journal publishers. It is currently publishing more than 200 open access, online, peer-reviewed journals covering a wide range of academic disciplines. SCIRP serves the worldwide academic communities and contributes to the progress and application of science with its publication.

Other selected journals from SCIRP are listed as below. Submit your manuscript to us via either submit@scirp.org or Online Submission Portal.
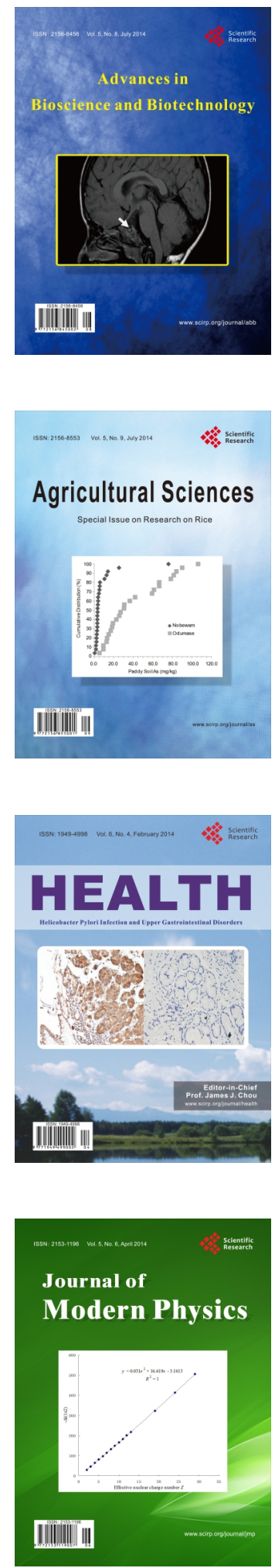
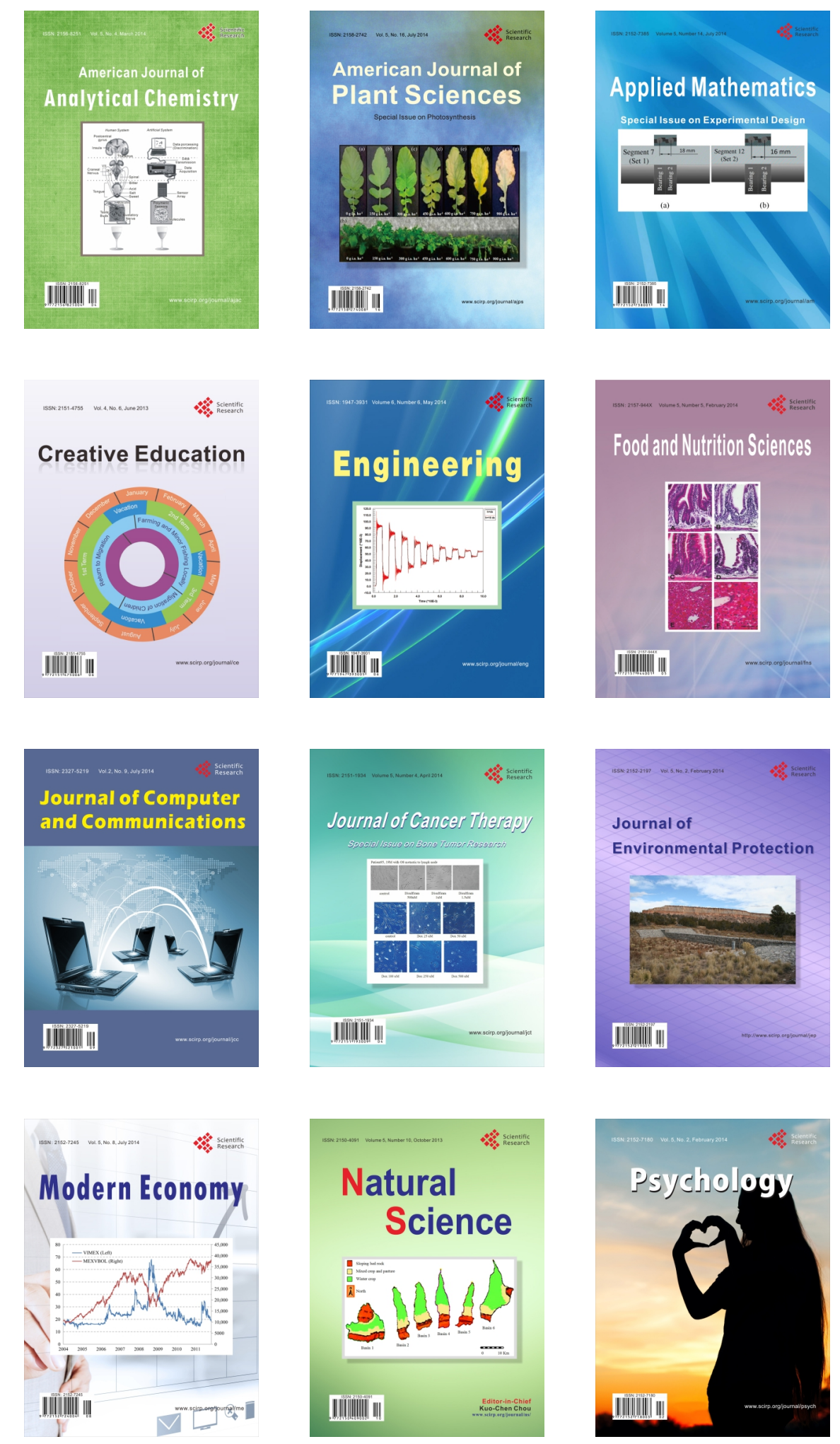